\title{
Design of Customizable Expressive Jewelry for Generation Z
}

\author{
Natasha Lynn Kusuma ${ }^{1}$ Eri Naharani Ustazah ${ }^{2}$ Hertina Susandari ${ }^{3}$ \\ ${ }^{I}$ Department of Product Design, Faculty of Creative Design and Digital Business, Institut Teknologi Sepuluh \\ Nopember (ITS), Surabaya 60111, Indonesia \\ ${ }^{2}$ Department of Product Design, Faculty of Creative Design, and Digital Business, Institut Teknologi Sepuluh \\ Nopember (ITS), Surabaya 60111, Indonesia \\ ${ }^{3}$ Department of Product Design, Faculty of Creative Design, and Digital Business, Institut Teknologi Sepuluh \\ Nopember (ITS), Surabaya 60111, Indonesia
}

Email:susan@prodes.its.ac.id

\begin{abstract}
Generation $\mathrm{Z}$ is the latest among the current living and working generations. They appreciate individuality and have their own personal style as a form of self-expression. Currently, they still have relatively low interest and purchase power on jewelry. Therefore, a jewelry that is able to be customized to match their personal style is designed. The aim of this design is to increase Generation Z's interest on jewelry product and for them to be able to express themselves in affordable price. The study of this design is conducted by exploring form, material, system and color. The used methods in this study are mood board, image board, and usability report. Mood board is used to promote inspiration in developing form and color based on the selected personal style, which is colorful indie. Image board is created based on two major keywords which inspires the jewelry system development. Usability report method is used for usability test, where participants are asked to wear the jewelry for seven days and give feedbacks for further revision. The result of this study is a handful of customizable components which are able to be assembled into earrings, necklace, and bracelet. Hopefully, this study can create awareness and appreciation to the jewelry industry as well as to serve useful information for the future study.
\end{abstract}

Keywords: Customizable, Generation Z, Jewelry, Self-expression.

\section{INTRODUCTION}

There are currently four living and working Generations, they are baby boomers, Generation X, Generation Y, and Generation Z. Generation Z is the latest generation among the other three. Generation $\mathrm{Z}$ are those who born between 1995 to 2012 [1]. In other words, they are now 8 to 25 years old. Unlike the other three generations, the top of this Generation $\mathrm{Z}$ is still currently in their early career and financial stage. Where they tend to spend their available income to fulfill basic needs. The experts say at this point jewelry doesn't really appeal Generation $\mathrm{Z}$ as they do not have the purchase power yet
[2]. However, in a few years from now they will be the jewelry industry consumer. Therefore, the industry must prepare and begin to increase their interest towards jewelry from now on.

In attempt to increase Generation Z's interest towards jewelry, it is necessary to know their jewelry preference that is also related to their characteristic. Various sources emphasize individualistic as one of this generation's characteristic. Such as in [2], it is said that Generation Z is proud of its individuality, creative, innovative, and wants to be empowered. As well as in [3], it is stated that Generation Z's nature is individualistic, realistic, and competitive. The individuality causes each member of this generation has their own personal style as a form of 
self-expression. This phenomenon later leads to an expected big trend of customization in jewelry industry, where Generation $\mathrm{Z}$ can create their own jewelry that is able to adapt with their respective style as a form of selfexpression.

\subsection{Related Work}

At the present time, there have not been many studies on customizable jewelry. In Indonesia itself, there is only one study as it can be seen in [4]. The background of the study is the lack of gold jewelry design which is in line with the jewelry trend in 2019 as a form of self-expression and investment for Gen Y or widely known as Millenial. The study resulted 4-in-1 stunning personalized or customizable jewelry design made of gold, that is able to be assembled into earrings, necklace, bracelet, and rings with tropical theme named "romantica forest".

\subsection{Contribution}

However, the previous study of customizable jewelry design segmentation is not Generation Z. Other than the segmentation gap, there also have not been any study on customizable jewelry which is specifically using material that is affordable by Generation Z. Whereas more familiar material like plastics, wood, stone, and composites could easily be explored in the workshop with the contemporary jeweler's practical skillset [5].

Therefore, the goals of this study are to design a jewelry that is able to be customized as a form of selfexpression for Generation $\mathrm{Z}$ and to reach their purchase power. It is aimed to increase Generation Z's interest on jewelry product and for them to be able to express themselves as well as giving solution for them to acquire it.

\section{LITERATURE REVIEW}

\subsection{Characteristics of Generation $Z$}

There are 7 keys characteristics of Generation $\mathrm{Z}$ as explained in the following section according to Cowan

[6] and another source [7].

a. Overprotected: Their parents always get rid of obstacles that lies in their way, so that they reach their future effortlessly.

b. Worldly: They communicate with people from all over the world and have a large of mixed-culture groups of friendship. It makes them very culturally accepting and have a truly global perspective.

c. Pragmatic: They share judiciously on social media, since they are used to filter and evaluate large amount of data whenever they look up for something.

d. Connected: They use smart gadgets like an extension of their body, and use emoji and meme to communicate with each other.

e. Creative: They agree that the freedom of expressing themselves through clothing is not to be taken for granted.

f. Pressured: They are signed into bolstered program of activities from art lessons, sports, language courses, to supplementary academic tuition.

g. Communitarian: They would rather learn from their peer groups than parents, and assume that everybody has the freedom to define everything for themselves

\subsection{Jewelry Classification}

Jewelry can be classified based on the used material and making process [8].

Fine jewelry: Sold at high price as it is made of precious metal and/ stone; high production cost; and complicated making process.

a. Costume jewelry: It is comprised into two types, which are fashion and traditional jewelry. The used material varies, such as plastic, wood, thread, glass, stone, acrylic, leather, textile, et cetera. The making process depends on the type of material.

b. Bridge jewelry: This can also be classified into contemporary jewelry. The cost of the materials is more likely to be higher than costume jewelry, as it uses mixed material with precious metal or stone. The making process is also more complicated to be compared with costume jewelry and it depends on the used material.

\subsection{Material and Form Exploration Using} Acrylic Sheets

Recent study shows that there are three techniques which are able to be implemented to achieve certain forms. The first technique is layering, which treatment is to stack acrylic sheets into layers. As a result of implementing this technique, it has depth effect that creates 3-dimensional form. The second technique is heating, where heat is used to create new form. The created new form is the material response to heat. The characteristic of the result of this technique is the new form has elasticity. The third technique is material mixing. It combines other material with acrylic sheet to create new shape. The characteristic of the result is it has embossed effect on the treated surface [10]. The three techniques are used as reference in conducting material and form exploration in this paper.

\section{METHOD}

The study of this design is conducted by doing exploration of system, material, form, and color. The main material exploration is performed on three different non-precious materials, namely imitation leather, 3dprinted plastic, and acrylic sheet. Several qualitative methods are used to support the system, form, and color explorations. The referred methods are image board, 
mood board, and usability report.

Image board and mood board are used to bring visual data altogether in imagery form, to promote inspiration in developing the product design. System related inspiration is obtained from image board, as it consists a collage of any other products than jewelry that represent two major key words. While form and color inspiration are most likely obtained from mood board that represents the one selected Generation Z member's style.

Martin and Hanington defined usability report as information of empirical evidence to help designer or teams decide whether product is usable enough to release, or needs revision and further testing with more participants [11]. Due to the limitation of the situation during the time of this study, this method is carried out by only two participants from Generation $\mathrm{Z}$ for seven days. Participants were asked to customize by assembling the available jewelry sets of components into different arrangement of earrings, necklace, and bracelet each day. After the data from the usability report is gathered and analyzed, the failures from the first prototype are revised to create a better second prototype which is the final design.

\section{FINDING AND RESULT}

\subsection{User Analysis}

The targeted user in this study is 17-25 years old female who lives in big city. Their financial status is also specified in middle up group, who are willing to spend up to Rp. 1.000 .000 on jewelry. In this paper, one personal style is selected to be the referenced persona in developing the design based on earlier study using indepth interview method on four Generation $\mathrm{Z}$ members. The result of the interview shows that the member with 'colorful indie' style has the highest purchase power to be compared with the other three. This style is unique, trendy, stands out in the crowd, vibrant, and has sense of retro appearance.

\subsection{Form Exploration}

The first thing to do in doing form and color exploration is to determine a themed series based on the persona and Generation Z's characteristics. The persona identity is cheerful, playful, self-assured, active, and creative. Generation $\mathrm{Z}$ wants to be empowered [2]. It becomes an inspiration in determining the series theme, which is self- empowerment. Through this series, the message that wants to be delivered is to support the targeted user in knowing and understanding themselves better as the first step in doing self-empowerment. To represent this message, the 7 characteristics of Generation $\mathrm{Z}$ is divided into what they are good at or strength, and what they are not good at or weakness. According to [6] and [7], the overprotected and pressured characteristics seem to be their weaknesses and shows that they want freedom in some ways as a highlight. Whereas the five other characteristics seem to be their strength, and often related to technology, internet, platform, and/ social media. One of the interesting parts about their characteristics is they communicate through emoji. From the two highlights, there comes the idea to use emoji that represents freedom. The emojis which have been determined by the authors are open hands, raising hands, raised fist, victory/peace hand, sunrise, dove, liberty, heart, lips, eye, and ear. Therefore, the first series is named "Break Free" and the most highlighted expression is cheerful.

Then mood board and image board are created. The mood board visualizes the persona and sense of freedom. It shows vibrant colors, playful patterns, colorful outfits, confetti, glitters, sky, and gestures that represents freedom and cheerful like jumping and opening arms. The image board shows images any other product than jewelry, that represents the main two major keywords in developing this design. The referred keywords are cheerful and customizable. Based on the image board, the system ideation is done.

The next step is doing the ideation process. It is done by sketching thumbnails of forms (and system, as both are related) ideas as many as possible. The result of this process is 30 pages of thumbnail sketches, which will be eliminated into five preliminary design alternatives. The selected form in preliminary design will be shown on system exploration section, where the system idea will be explained in details.

\subsection{Material Exploration}

Acrylic sheet is chosen because the other two materials cannot achieve certain forms and small sizes in jewelry parts. The production time and process are also more effective. The exploration of the chosen material is focused in 1) analyzing pendants and chains in different forms and sizes; 2) bending using the heating technique to create a long hanging hands shaped necklace; 3) the best type and thickness to use; and 4) coloring technique using pigmented and glittered resin. The result of the first analysis is this material can reach various flat chains forms in many sizes. But it breaks more easily than the $3 \mathrm{~d}$-printed pieces. The second analysis resulted this material is very interesting to be explored using the heating technique, but the direction of this study is more likely to use the layering technique due to the effective making process. The third analysis resulted the $2 \mathrm{~mm}$ and $3 \mathrm{~mm}$ transparent acrylic are the best to be used. It is because they are the easiest to find in the market, and durable enough for jewelry. The last analysis also gives attractive results which coloring technique can be applied into the final design. Some of the analyses results can be seen in Figure 1. 


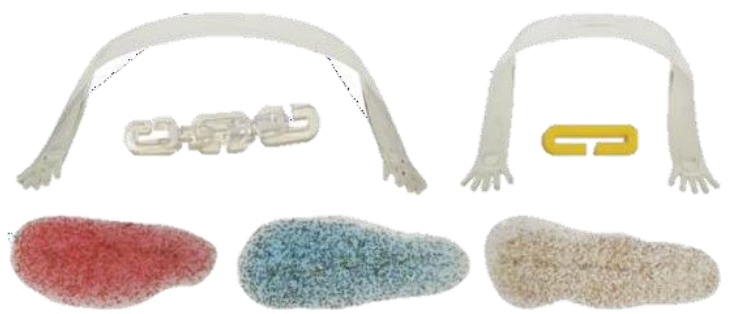

Figure 1 Acrylic Sheet Material Exploration: Coloring, Forms, Types, and Sizes.

From the explanation above, it can be concluded that acrylic is used to be the main material in this study. To be more specific, $3 \mathrm{~mm}$ acrylic is more dominant rather than the $2 \mathrm{~mm}$ thick. But other material such as $3 \mathrm{~d}$-printed resin can also be used as support to create certain component with specific function like chain end.

\subsection{System Exploration}

There are five alternatives of preliminary design which consists of different systems. The five alternatives are necklaces, as this type of jewelry is the largest to be compared to the other types. Which means it has more complex system. The first alternative offers customizable chains, and alphabetic beads that is assembled in two layered removable cords. The second alternative offers leather and chain layered choker. It has customizable pendants with button system on the choker, and hanging system on the chains. The third alternative consists of necklace base in long hanging hands form that wraps the neck and shoulders with removable layered chains that connect each hand. It also offers customizable hanging pendants on the chains. The fourth alternative is metal plated choker, which offers customizable pendant with sliding system like bobby pin. The last alternative offers a few of different customizable components, such as cord with alphabetical beads; horizontal pendant; and chains in long, big and medium size.

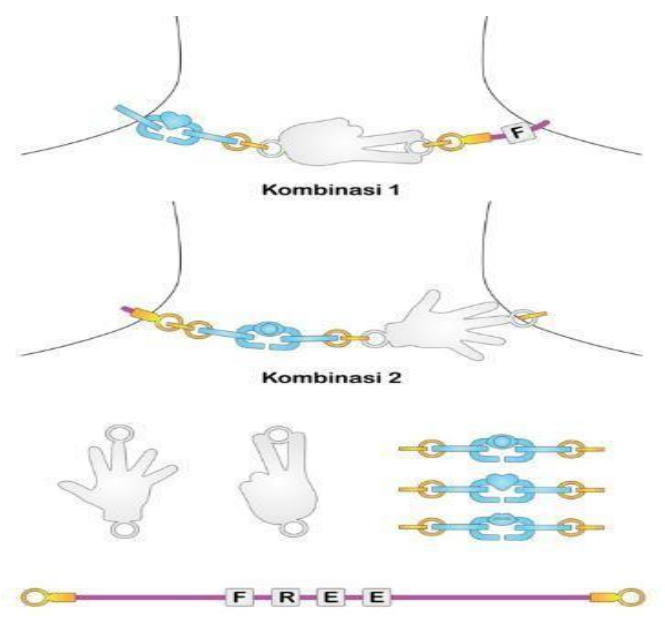

Figure 2 The Fifth Preliminary Design Alternative.
The chosen alternative as preliminary design is the fifth alternative, which is shown in Figure 2. It is chosen because it has more component variants. They are able to be assembled without any basis to be compared with the other four alternatives. The advantages allow the user to assemble their own preferred jewelry freely into earring, necklace, and bracelet.

After the preliminary design is chosen, then design detailing is needed to be done before going into the prototyping process. The detailed design resulted 13 components which are described as follows, and the image is shown in Figure 5.

1. Small chains set: three small chains $(20 \times 10 \times 3$ $\mathrm{mm})$ with one circle connector. All of the circle connector in this design is $15 \mathrm{~mm}$ sized, made of $3 \mathrm{~mm}$ acrylic.

2. Long chain set: one long chain ( $40 \times 10 \times 3 \mathrm{~mm})$ and one connector.

3. Big chains set: three big chains $(30 \times 15 \times 3 \mathrm{~mm})$ and one connector.

4. Wings and Liberty chains set: one big chain with petite wings and liberty crown shaped pendants, two big chains, and one connector.

5. Smoochies and Hearties chains set: one big chain with lips and heart shaped pendants, two big chains, and one connector.

6. Eyes and Ears chains set: one big chain with eye and ear shaped pendants, two big chains, and one connector.

7. The Yay Pendant: open hand shaped horizontal pendant with $65 \mathrm{~mm}$ length.

8. The Peace Pendant: peace hand shaped horizontal pendant with $65 \mathrm{~mm}$ length.

9. The Custom Earring: Uses a pair of big chain part, which are glued to earring posts. It includes tension earring backs.

10. The Strong Line: alphabetical beads in different colors which arranged into the word 'strong', on 3 $\mathrm{mm}$ plastic tube with resin-based $3 \mathrm{~d}$-printed chain ends on each side of the tube.

11. The Happy Line: alphabetical beads in different colors which arranged into the word 'happy', on 3 $\mathrm{mm}$ plastic tube with resin-based $3 \mathrm{~d}$-printed chain ends on each side of the tube.

12. The Love Line: alphabetical beads in different colors which arranged into the word 'love', on 3 $\mathrm{mm}$ plastic tube with resin-based $3 \mathrm{~d}$-printed chain ends on each side of the tube.

13. The Free Line: alphabetical beads in different colors which arranged into the word 'free', on 3 $\mathrm{mm}$ plastic tube with resin-based $3 \mathrm{~d}$-printed chain ends on each side of the tube.

4.5 Color Exploration

Acrylic based parts color determination is carried out 
along the prototyping process. The acrylic is painted with pigmented and glittered resin. After going into trials and errors in prototyping, there are finally two options of color combination which represents the colorful indie persona and cheerful expression. Both color combination options are mixed with four colored glitter. The codes of color combination options and glitters can be seen in Figure 3.

\subsection{Usability Test}

After the prototype is made, usability report method is done by two participants. They are asked to create different earrings, necklace, and bracelet assembly for 7 days. The usage time per day is only 2 hours. The data from the report is gathered and analyzed subsequently. The final result of the usability test is stated as follows.

1. The users' first impression on the jewelry is excited and interested. One of the users said it is cute.

2. The average time needed to create earrings, necklace, and bracelet assemblies at a time is around 15 minutes.

3. Asymmetric assembly gives more playful and cheerful impression.

4. As two users have different wrist and neck size, the components set can be adjusted. The adjustment is done by removing one part from the component. As an example, small chains set is often adjusted by removing one or two chain parts.

5. The earrings can be used as single earring. It gives more attractive impression to the user.

6. The assembly is easy to fall off before it gets worn.

7. The edges of the acrylic based components are a little bit sharp when it presses the skin.

8. The pendants fall off the most to be compared to the other components. It is because the size is too big, and the permanently attached connector shape is not suitable with the assembly system.
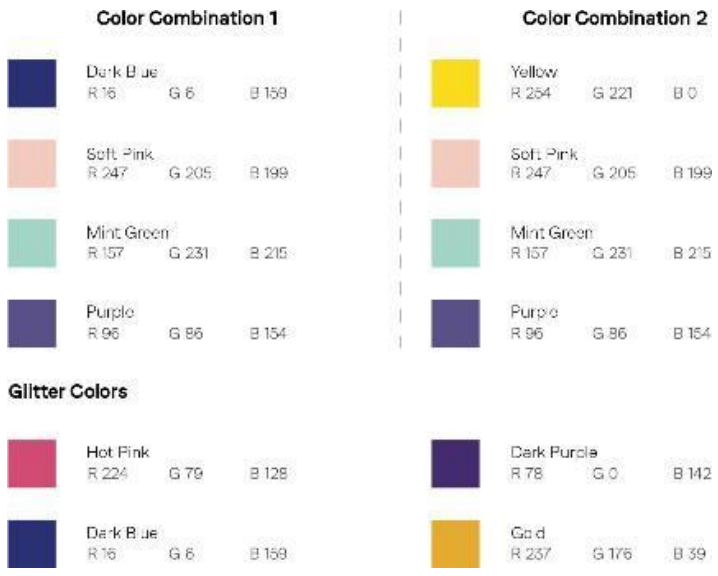

Figure 3 Color Codes of Resin Paints Color
Combinations and Glitter.

\subsection{Design Revi sion}

Regarding to the sharp edges of the acrylic based components, the author tried to blunt it using sand papers manually. The result of the sanded edges is relatively cannot achieve straight and precise curve. Due to the limited access, facility, and tools during the study this matter cannot be revised any further. The pendant size is changed from $65 \mathrm{~mm}$ to $45 \mathrm{~mm}$ length. The permanently attached connector on each side of the first prototype of both pendants has a gap. The gap seems to be the reason they fall off easily. The needed revision regarding to this matter is to remove the gap into a complete circular form which can be seen in the following figure.

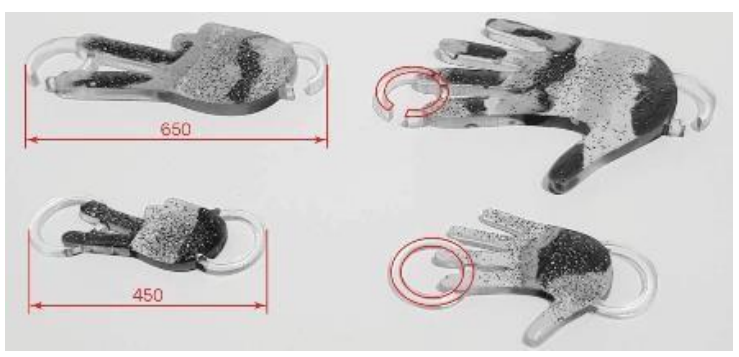

Figure 4 Revision of Pendants Design.

\subsection{Final Design}

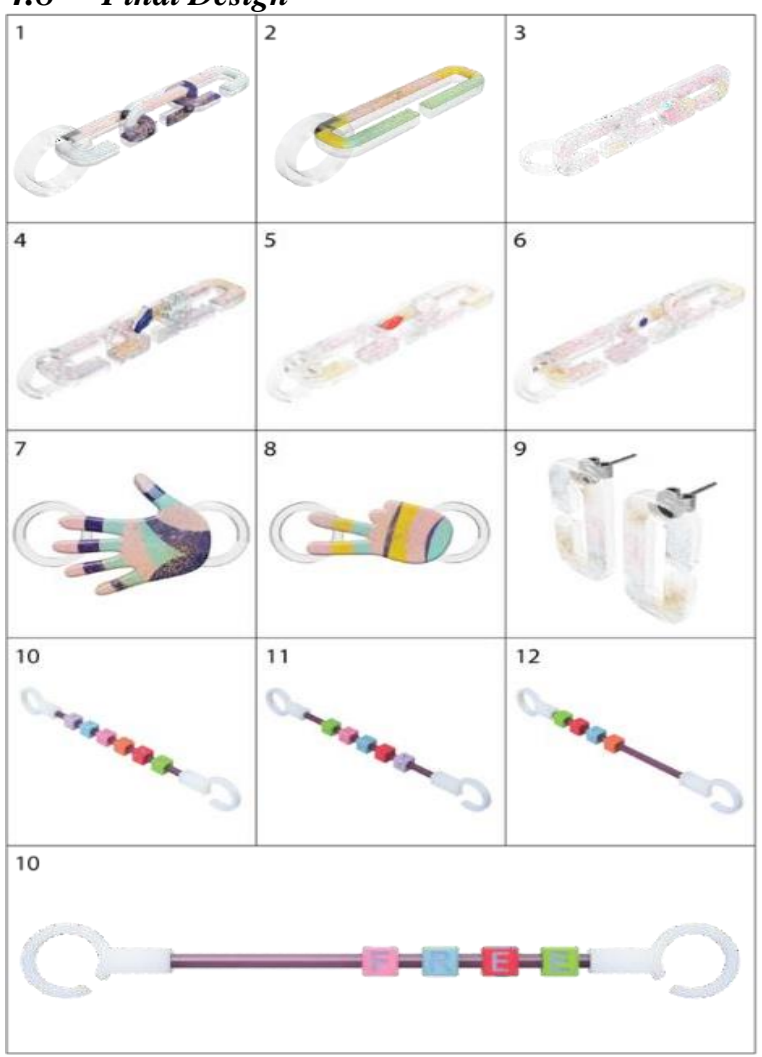

Figure 5 3D Model of Customizable Components 


\section{Final Design}

Figure 5 shows 3D models of the components final design. While Figure 6 to Figure 8 show the worn second prototype documentation. The 3D models have been sorted by the order of the mentioned components in system exploration section. The prototype documentation highlights three assembly alternatives for earrings, necklace, and bracelet.

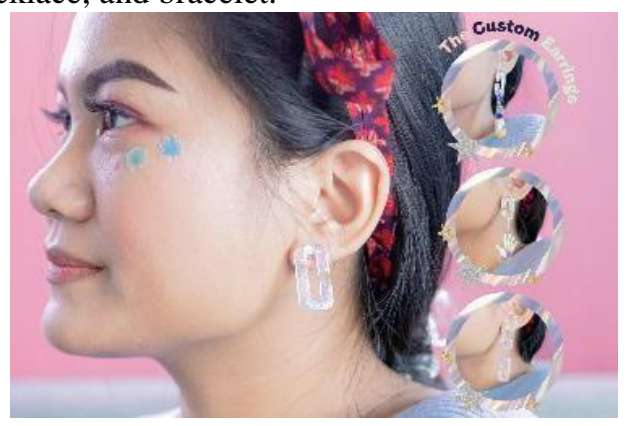

Figure 6 Prototype Documentation: Earrings Assembly Alternatives.

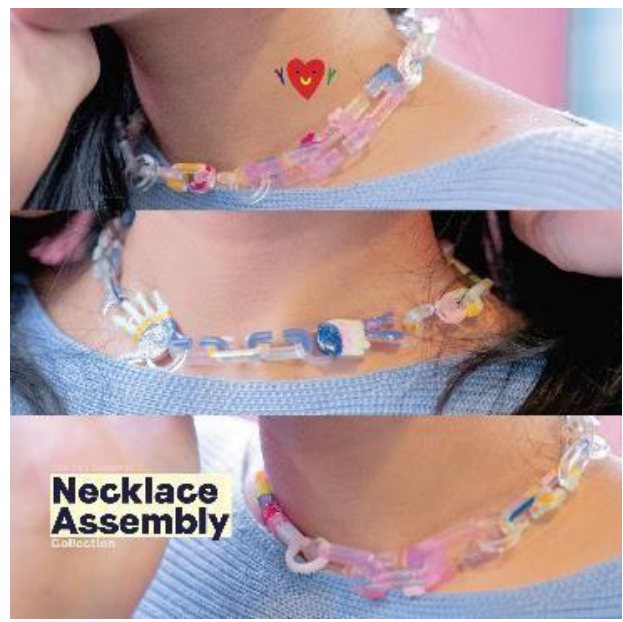

Figure 7 Prototype Documentation: Necklace Assembly Alternatives.

\section{CONCLUSION}

Generation Z still has a relatively low interest and purchase power towards jewelry. But it is necessary for the jewelry industry to start approaching this generation from now, by offering an affordable jewelry that matches with their personal style as a form of self-expression. In this study, a series of customizable jewelry named "Break Free" is designed. The message that wants to be delivered is about self-empowerment, that encourages Generation $\mathrm{Z}$ to know and understand themselves better as well as claiming their freedom. This series consists of 13 components which are able to be freely assembled by the user. The used materials are not precious, regarding to the current Generation Z's purchase power. It is mainly to be $2 \mathrm{~mm}$ and $3 \mathrm{~mm}$ thick of acrylic sheets with pigmented and glittered resin paint. But other materials such as $3 \mathrm{~d}-$ printed resin, beads, plastic tube and metal earring findings are also used for certain parts and components. However, there are still a lot to be improved from the current result of this study. The authors suggest the future study to improve the current system, the finishing process for the acrylic edges, and the user related analysis using any other design methods. Hopefully, this study can create awareness and appreciation to the jewelry industry, and serve useful information to the future study.

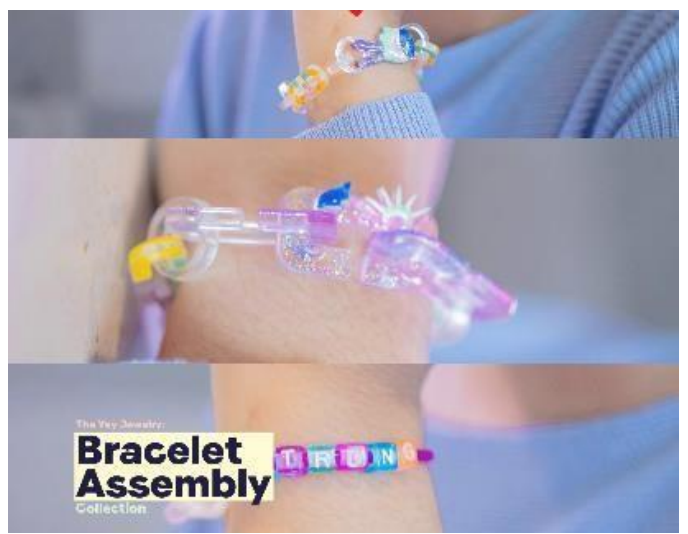

Figure 8 Prototype Documentation: Bracelet Assembly Alternatives.

\section{REFERENCES}

[1] M. S. M. Salleh, N. N. Mahbob and N. S. Baharudin, "Overview of "Generation Z" Behavioural Characteristic and Its Effect Towards Hostel Facility," International Journal of Real Estate Studies, vol. 11, no. 2, pp. 59-67, 2017.

[2] T. W. Strauss, "Generation Z: Future Jewelry Consumers," Ganoskin: Jewelry Making Resources, [Online]. Available: https://www.ganoksin.com/article/generation-zfuture- jewelry-consumers/. [Accessed 27 July 2020].

[3] S. L. Sladek and A. Grabinger, "Gen Z: The First Generation of The 21st Century Has Arrived!," 08 2018. [Online]. Available: https://www.xyzuniversity.com/wpcontent/uploads/2018/08/GenZ_Final-dl1.pdf. [Accessed 27 July 2020].

[4] A. Nadira, "Desain Perhiasan Emas Milenial dengan Sistem Personalized," Institut Teknologi Sepuluh Nopember, Surabaya, 2019.

[5] K. Vones, "Materials Libraries - A Jeweller's Perspective," Journal of Jewellery Research, vol. 1, pp. 34-50, 2018. 
[6] M. Cowan, Generation Z: The New Kids On The Block Have Arrived, London: Happen Group, 2014.

[7] E. Cunningham, "The Z List: 29 Teens Changing Fashion," Refinery29, [Online]. Available: https://www.refinery29.com/en-us/the-z-list/. [Accessed 27 July 2020].

[8] A. Arumsari, "Contemporary Jewelry Trend as a Result of People Lifestyle's Changes and Fashion Industries Development in Indonesia," International Journal of Humanities Social
Sciences and Education (IJHSSE), vol. 2, no. 11, pp. 68-77, 2015.

[9] M. N. Putri and D. Ismail, "Pemanfaatan Teknologi Laser Cutting dalam Proses Perancangan Perhiasan Berbahan Akrilik Lembaran dengan Pendekatan Eksplorasi Bentuk," Jurnal Desain Indonesia, vol. 2, no. 1, pp. 24-33, 2020.

[10] B. Martin and B. Hanington, Universal Methods of Design, Beverly: Rockport Publishers, 2012. 